\title{
NL Model on Traffic Mode Split among High-density Town Cluster
}

\author{
Shimei $\mathrm{Wu}^{1,}$, , Yulong Pei ${ }^{1, b}$ \\ ${ }^{1}$ School of Transportation Science and Engineering, Harbin Institute of Technology, Harbin 150090, \\ China \\ ${ }^{1}$ DongGuan Development and Reform Bureau, DongGuan 523888, China \\ ${ }^{2}$ School of Transportation Science and Engineering, Harbin Institute of Technology, Harbin 150090, \\ China \\ aemail: s0825r@qq.com, bemail: yulongp@263.net
}

Keywords: transportation planning; high-density town cluster; traffic travel mode; NL model; multi-mode rail transit

\begin{abstract}
With urbanization process acceleration in China, traffic travel among cities becomes increasing, and traffic mode split is the key link of traffic passenger flow forecast among cities. In this paper, the concept of high-density town cluster was proposed to analyze the characteristics of development, population composition, and traffic facilities among high-density town cluster. Based on applicability analysis of aggregate model and disaggregate model, survey content of revealed preference (RP) and stared preference (SP), and traffic mode hierarchical division according to average speed, then NL disaggregate model among high-density town cluster was constructed. NL model which was parameter calibrated and validated with DongGuan citizen travel investigation data in 2009 was used to analyze the trend of traffic mode split. The result shows that high-density town cluster, such as DongGuan, are establishing a three-dimensional travel mode set, including high-speed rail, intercity rail, suburban rail, urban rail transit, intercity express bus, car, taxi, and common public transport. With the network of multi-mode rail transit further improving, ratio on choosing the traffic mode of multi-mode rail transit, such as high-speed rail, intercity rail, suburban rail, urban rail transit, increases dramatically.
\end{abstract}

\section{Introduction}

Recently years, with the number of traveling among cities, such as Pearl River Delta Area, Yangtze River Delta Area, Bohai Area, and so on, increased dramatically, and the travelers require that the transportation should be rapid, comfortable, and safe. However, traditional train, bus, and taxi don't meet the requirement mentioned before. On this condition, the planning and construction of high speed train, intercity rail transit, and suburb railway accelerate dramatically. However, passenger traffic forecasting which plays an important role in the planning and construction of rail transit is not well carried out, or be a mere formality. Therefore, passenger traffic forecasting cannot suit for the development of transportation among cities, strengthening the research on passenger traffic forecasting is very necessary and urgent.

\section{Definition of High-density Town Cluster}

At present, China has formed some high-density town clusters, such as Pearl River Delta Area, Yangtze River Delta Area, Beijing-Tianjin-Hebei region, Changsha-Zhuzhou-Xiangtan region, West coast, Liaoning province coastal belt, and so on.

Like the term of high-density town cluster, there are still other terms, such as urban agglomeration, big city belt, urban development region, urban high-density area, and so on. Domestic scholars have studied and analyzed these terms (Li X. J, 2008). According to these terms' definition, the high-density town cluster is defined in this paper. 
Based on development pattern and space distance, high-density town cluster is defined of region where cities and towns rapid develop simultaneously, distances among the centers of cities are less than 100 kilometers, travel time by freeway among the centers of cities are less than one hour, distances between adjoin towns are less than 10 kilometers, travel time by urban aerial roads between adjoin towns are less than 10 minutes, are formed by different town clusters, the functions of which are related to each other, and connect frequently.

\section{Forecasting Model Choice}

The forecasting model can be divided into aggregate models and disaggregate models. Aggregate models are based on the traditional "Four-stage method" (Lu H. P., 1998).

Aggregate models are based on the traditional "Four-stage method". Disaggregate models attempt to analyze these problems, like whether the individual of traffic behavior decision-maker unit travel or not, where to go, use what mode of transportation, and choose which path, and so on. Modeling and summation of each traveler how to choose the best selection branches, then total traffic demand can be calculated. Disaggregate model which is discrete choice model based on maximum effect theory includes Logit model (MNL model), Probit model, NL model, Mixed Logit model, and some other models like that (Kenneth, 2003; Guan, 2004).

NL model overcomes the problem of mutual independence of non-related options for MNL model. What's more, NL model solution is much easier than Probit model, expresses the relevance of options in some extent at the same time (Hensher, et al., 2002). Therefore, NL model is chosen to establish the mode of intercity travel mode choice in high-density town cluster.

\section{Model Established}

Resident travel investigation (revealed preference, RP) and resident travel intention survey (stared preference, SP) were conducted in 2009 for the development and planning of rail transits network in Dongguan. Survey content includes personal socio-economic characteristics (gender, age, profession, educational background, income), household socio-economic characteristics (home address, family members, household income, household car and number of bicycles), activities chain investigation data (activity purpose, start time, travel distance, travel mode, travel fee, whether transfer the transport) and resident travel intention survey on the presume that multiple modes rail transits network is built; stations are set; and the ticket prices are difference. All these survey data provide the necessary foundation for confirming the option branches and selecting the variables in RP model and SP model.

\section{Determining of Choice Branch}

In the RP investigation, intercity traffic modes which resident can choose in Dongguan include suburb rail, intercity rapid bus, intercity bus, taxi, car, however, walk and bicycle are not considered due to travel distance. Choice branches are confirmed by the main travel way during the process of modeling. For instance, if one travel way includes walk, bus, and intercity rapid bus, and the choice branch is intercity rapid bus; if one travel way includes car and intercity railway, and the choice branch is intercity railway. In the SP survey, intercity travel modes for Dongguan resident choosing have increased high speed railway, intercity rail transit, and urban rail transit. 


\section{MNL model}

Options of MNL model can be divided into multiple layers by relevance, each layer is one model, and every two layers can be connected by logarithm of the lower layer total utility. The theoretical foundation of MNL model is that traveler chooses the maximum utility project under the special choice condition. MNL model can be expressed as following (Zhang, et al., 2008).

$$
\begin{aligned}
& U_{i, n}=V_{i, n}+\xi_{i, n} \\
& P_{i, n}=\frac{\exp \left(\lambda V_{i, n}\right)}{\sum_{i=1}^{N} \exp \left(\lambda V_{i, n}\right)}
\end{aligned}
$$

Where, $U_{i, n}$ is the utility function when traveler $\mathrm{n}$ chooses the $i$ travel project. parameter $V_{i, n}$ is constant variable, and $\xi_{i, n}$ is probability. MNL model assumes that $\xi_{i, n}$ subject to the double exponential distribution, and all variables are pair wise independent. $P_{i, n}$ is the probability of traveler $\mathrm{n}$ chooses the $i$ travel project. $N$ is the number of travel projects for choosing. RP model and SP model can be established owing to the difference of survey mode and content. SP model presumes that both the probability of SP and RP have the same distribution.

\section{Influence Factor Model of Utility Value}

There are many factors which influence residents in high-density town cluster travel. Travel time, travel fee, household income, and the qualitative variables constituted by convenience, comfort, and security are chosen to as the model variables.

Utility functions include linear function, logarithmic function, and so on. The linear function is widely used, and its expression is intuitive, and easy to solve. Which is shown as following

$$
V_{i n}=\sum_{k=1}^{K} \theta_{k} X_{i n k}
$$

Utility function of high-density town cluster resident for intercity traveling is expressed.

$$
V_{\text {in }}=\theta_{1} T+\theta_{2} F+\theta_{3} S+\theta_{4} R
$$

Where, $T$ indicates travel time, including transport travel time, transport connected run time, waiting time, transferring time, and so on; $F$ indicates travel fee, including ticket price, parking fee, tolls, fuel cost, and so on; $S$ is household income, which is related to other influence factors; $R$ is qualitative variable, including convenience, comfort, security, and so on; According to the quantitative methods researched by home and abroad scholars, the service level of different traffic modes can be divided into highest, higher, common, low four grades, and the value range is $(4,0)$, which is chosen by travelers.

\section{Traffic Mode Hierarchical Division}

In the Dongguan investigation, residents pay close attention to the travel time when they choose the intercity travel traffic mode, and travel time is closely related to operation speed of transport. Hence, traffic mode hierarchical division is based on operation speed of the main transport.

Virtual mode 1: travel mode which its average operation speed is up to over $200 \mathrm{~km} / \mathrm{h}$ is high speed railway.

Virtual mode 2: travel modes which their average operation speeds are between $100 \mathrm{~km} / \mathrm{h}$ and $200 \mathrm{~km} / \mathrm{h}$ are intercity rail transit and suburb railway. 
Virtual mode 3: travel modes which their average operation speeds are between $60 \mathrm{~km} / \mathrm{h}$ and 100 $\mathrm{km} / \mathrm{h}$ are urban rail transit, urban rapid bus, private vehicle, officer vehicle, and taxi.

Virtual mode 4: travel modes which their average operation speeds are amount to under $60 \mathrm{~km} / \mathrm{h}$ are intercity common bus, individual vehicles for short distance travel, such as private vehicle, officer vehicle, and taxi.

Therefore, probability calculation formula for variety of traffic modes is expressed as.

$$
P_{A_{i n}}=P_{(i \mid A) n} P_{A n}
$$

Where, $A_{i n}$ is the $i$ choice branch under virtual mode A; $P_{A_{\text {in }}}$ is the probability of traveler $n$ choosing mode $A_{i} ; P_{(i \mid A) n}$ is the probability of traveler $n$ choosing mode $i$ based on virtual mode A; $P_{A n}$ is the probability of traveler $n$ choosing virtual mode $A$.

\section{Parameter Calibration}

Parameters $\theta_{1} \sim \theta_{4}$ are calibrated by maximum likelihood estimation method. Choice result is defined as constant term, and when the traveler $\mathrm{n}$ chooses mode $i$, constant term is 1 ; or not, constant term is 0 . Estimation methods of parameter $\theta_{1} \sim \theta_{4}$ include N-R, D-F-P, and H-J, which will not detailed discuss (An, 2004).

\section{Mode Validation and Trend Analysis}

RP and RP surveys were conducted in Dongguan in 2009 and relevant data with ESS(effective sample size) of 6000 were collected, which distributed in 32 towns and streets in the whole city. Those data were organized and applied in Rail Transit Network Planning and Adjustment for Dongguan. we chose Multi-Logit module in SPSS.

\section{Mode Validation}

Table 1 Parameters for Different Intercity Trip Modes in Dongguan in 2012

\begin{tabular}{c|c|c|c|c|c|c|c|c}
\hline Trip Mode & $\theta_{1}$ & $t$ statistic & $\theta_{2}$ & $t$ statistic & $\theta_{3}$ & $t$ statistic & $\theta_{4}$ & $t$ statistic \\
\hline $\begin{array}{c}\text { High-speed railway } \\
\begin{array}{c}\text { Guangzhou-Shenzhen } \\
\text { bullet train }\end{array}\end{array}$ & -0.1354 & 2.35 & -0.1632 & 3.22 & 0.1090 & 2.87 & 0.0624 & 3.11 \\
\hline Intercity rail transit & $/$ & 3.21 & -0.0936 & 2.33 & 0.0959 & 2.57 & 0.0663 & 2.89 \\
\hline Urban rail transit & $/$ & $/$ & $/$ & $/$ & $/$ & $/$ & $/$ & $/$ \\
\hline Intercity rapid bus & -0.1061 & 1.99 & -0.2071 & 4.35 & -0.0245 & 3.79 & 0.0482 & 4.13 \\
\hline Private cars & -0.1873 & 2.05 & -0.1104 & 3.88 & 0.1433 & 2.89 & 0.0457 & 3.57 \\
\hline Taxi & -0.2232 & 5.34 & -0.0874 & 2.19 & 0.1123 & 2.67 & 0.0087 & 6.28 \\
\hline Official vehicles & -0.2466 & 4.26 & -0.0017 & 2.87 & 0.0029 & 3.36 & 0.0454 & 3.33 \\
\hline Intercity Bus & -0.0252 & 2.65 & -0.2853 & 3.26 & -0.1784 & 4.38 & 0.0026 & 2.68 \\
\hline Short distance & -0.0133 & 3.11 & -0.0204 & 2.77 & -0.1328 & 3.25 & 0.0011 & 4.36 \\
\hline
\end{tabular}

Generally, we use $t$ statistic and $\rho^{2}$ in Statistics \& Probability to validate a mode by conducting $t$ test on single variable. If $|t| \geq 1.96$, it can be said that $t$ test pass muster, as for $\rho^{2}$, if it is between 0.2 to 0.4 ,we can conclude that the mode fits well. 
From the data collected in the survey in Dongguan in 2012, we got various parameters for different travel modes which are shown in table 1.

It can be seen from the table that each $t$ statistics of parameters for different intercity trip modes meet the request that $|t| \geq 1.96$, which means relevant parameters meet requirement.Predicted value of the mode for 2005 and 2009 can be calculated by SPSS, which can be seen in table 2.

Table 2 Comparison of predicted value with survey value of proportion of different intercity trip modes in Dongguan

\begin{tabular}{|c|c|c|c|c|c|c|c|c|c|c|}
\hline \multirow[b]{2}{*}{ Year } & \multirow{2}{*}{$\begin{array}{c}\text { A1 } \\
\text { High } \\
\text {-speed } \\
\text { railway }\end{array}$} & \multicolumn{2}{|c|}{$\mathrm{A} 2$} & \multicolumn{5}{|c|}{ A3 } & \multicolumn{2}{|c|}{ A4 } \\
\hline & & $\begin{array}{l}\text { Guangzhou } \\
\text {-Shenzhen } \\
\text { bullet train }\end{array}$ & $\begin{array}{c}\text { Intercity } \\
\text { rail } \\
\text { transit }\end{array}$ & $\begin{array}{l}\text { Urban } \\
\text { rail } \\
\text { transit }\end{array}$ & $\begin{array}{l}\text { Intercity } \\
\text { rapid } \\
\text { bus }\end{array}$ & $\begin{array}{c}\text { Private } \\
\text { cars }\end{array}$ & Taxi & $\begin{array}{c}\text { Official } \\
\text { vehicles }\end{array}$ & $\begin{array}{c}\text { Intercity } \\
\text { bus }\end{array}$ & $\begin{array}{c}\text { Short } \\
\text { distance } \\
\text { vehicles }\end{array}$ \\
\hline 2005 & 0 & 0.196 & 0 & 0 & 0.457 & 0.174 & 0.088 & 0.031 & 0.033 & 0.021 \\
\hline $\begin{array}{c}\text { survey } \\
\text { value }\end{array}$ & 0 & 0.187 & 0 & 0 & 0.462 & 0.180 & 0.082 & 0.033 & 0.035 & 0.021 \\
\hline Error & 0 & $4.81 \%$ & 0 & 0 & $-1.08 \%$ & $-3.33 \%$ & $7.32 \%$ & $-6.06 \%$ & $-5.71 \%$ & $0 \%$ \\
\hline 2009 & 0 & 0.188 & 0 & 0 & 0.473 & 0.162 & 0.094 & 0.035 & 0.031 & 0.017 \\
\hline $\begin{array}{l}\text { survey } \\
\text { value }\end{array}$ & 0 & 0.193 & 0 & 0 & 0.480 & 0.157 & 0.089 & 0.032 & 0.030 & 0.019 \\
\hline Error & 0 & $-2.59 \%$ & 0 & 0 & $1.46 \%$ & $3.18 \%$ & $5.62 \%$ & $9.38 \%$ & $3.33 \%$ & $10.53 \%$ \\
\hline
\end{tabular}

It can be seen from the table that errors of predicted value compared to survey value are small and prediction results of trip modes which accounted for a larger proportion such as Guangzhou-Shenzhen Bullet Train, Inter-city Rapid Bus transit; Private Cars and Taxi are more accurate. And $\rho^{2}$ value of this mode is 0.338 which means the mode fits well.

\section{Trend Analysis}

Guangzhou-Shenzhen Bullet Train in Dongguan will be formally opened to public in 2012 . Intercity rail transit of Guangzhou-Dongguan-Shenzhen and Dongguan-Huizhou and Urban Rail Transit R2 is still under construction while Foshan-Dongguan Intercity rail transit is still under planning.Intercity travel modes proportions in Dongguan among 2009, 2012, 2015, and 2020 are shown in table3.

Table 3 Intercity travel modes proportion in Dongguan

\begin{tabular}{|c|c|c|c|c|c|c|c|c|c|c|}
\hline \multirow[b]{2}{*}{ Year } & A1 & \multicolumn{2}{|c|}{$\mathrm{A} 2$} & \multicolumn{5}{|c|}{ A3 } & \multicolumn{2}{|c|}{ A4 } \\
\hline & $\begin{array}{l}\text { High } \\
\text {-speed } \\
\text { railway }\end{array}$ & $\begin{array}{l}\text { Guangzhou } \\
\text {-Shenzhen } \\
\text { bullet train }\end{array}$ & $\begin{array}{c}\text { Intercity } \\
\text { rail } \\
\text { transit }\end{array}$ & $\begin{array}{l}\text { Urban } \\
\text { rail } \\
\text { transit }\end{array}$ & $\begin{array}{l}\text { Intercity } \\
\text { rapid bus }\end{array}$ & $\begin{array}{c}\text { Private } \\
\text { cars }\end{array}$ & Taxi & $\begin{array}{l}\text { Official } \\
\text { vehicles }\end{array}$ & $\begin{array}{c}\text { Intercity } \\
\text { bus }\end{array}$ & $\begin{array}{c}\text { Short } \\
\text { distance } \\
\text { vehicles }\end{array}$ \\
\hline 2009 & 0 & 0.188 & 0 & 0 & 0.473 & 0.162 & 0.094 & 0.035 & 0.031 & 0.017 \\
\hline 2012 & 0.063 & 0.166 & 0 & 0 & 0.467 & 0.139 & 0.085 & 0.034 & 0.030 & 0.016 \\
\hline 2015 & 0.075 & 0.138 & 0.103 & 0.078 & 0.372 & 0.094 & 0.063 & 0.033 & 0.028 & 0.016 \\
\hline 2020 & 0.077 & 0.112 & 0.175 & 0.145 & 0.278 & 0.082 & 0.059 & 0.033 & 0.025 & 0.014 \\
\hline
\end{tabular}

We can see from the forecast result, intercity travel mode structure will change, with the rapid construction and operation of Dongguan passenger traffic facilities over the year of 2009, 2012, 2015, and 2020. With the further improvement of high speed railway and intercity railway network, 
choice proportions of multiple rail transits composed by high speed railway, intercity railway, suburb railway, and urban rail transit will dramatically increase, ranging from 0.188 in the year of 2009 to 0.229 in the year of 2012, and ascending from 0.394 in the year of 2015 to 0.509 in the year of 2020, while that of intercity rapid bus, private cars, and taxi will gradually decrease. However, the choice proportions of official vehicles, intercity bus, and short distance vehicles will remain the same level.

\section{Conclusion}

Nowadays, planning and construction of high speed railway, intercity rail transit, and urban rail transit are in the period of accelerate development, passenger flow forecasting is significant for determining the construction projects and scales, and travel mode choice is an important step of passenger flow forecasting. Study on NL model of travel mode choice in high-density town cluster will play a reference role in the process of similar cities or regions planning.

\section{References}

[1] X. J. Li. Town high-density area and town cluster planning-practices and understanding. Journal of Urban Planning, (2008) 1-7.

[2] H. P. Lu. Theory and method in transportation planning. Tsing Hua University Press. 1998, pp. 56-73.

[3] Kenneth E Train. Discrete choice methods with simulation. Cambridge University Press, 2003, pp. 45-62.

[4] H. Z. Guan. Disaggregate Model-Traffic Behavior Analysis Tools. China Communications Press, 2004, pp. 27-42.

[5] H. R. Zhu. Study on traffic behavior characteristics and traffic mode choice based on activity analysis. Tongji University, (2005) 32-36.

[6] Hensher D, Greene W. Specification and estimation of the nested logit model: Alternative Normalizations. Transportation Research B, 36 (2002) 3-15.

[7] H. R. Zhang, G. Ren, W. Wang. Application of discrete choice model in trip mode structure forecasting. Journal of Transportation Systems Engineering and Information Technology, 5 (2008) 44-49.

[8] A. Jin. On methodology of parameter estimation in logit model. Journal of Transportation Systems Engineering and Information Technology, 4 (2004) 71-75.

[9] W. T. Zhang. SPSS 11 Statistical Analysis Course. Beijing, 2002. 